\title{
Influence of Social Network Strength on Entrepreneurial Opportunity Recognition: A Chain Mediation Model of Need Knowledge and Technological Knowledge
}

\author{
Jing Fan $\mathbb{D}^{1,2}$ and Jiafu Su $\mathbb{D}^{3}$ \\ ${ }^{1}$ International College, National Institute of Development Administration, Bangkok 10240, Thailand \\ ${ }^{2}$ School of Economics and Trade, Guangxi University of Finance and Economics, Nanning, Guangxi 530007, China \\ ${ }^{3}$ National Research Base of Intelligent Manufacturing Service, Chongqing Technology and Business University, \\ Chongqing 400067, China
}

Correspondence should be addressed to Jing Fan; jing.fan@gxufe.edu.cn

Received 18 September 2021; Revised 21 October 2021; Accepted 22 October 2021; Published 9 November 2021

Academic Editor: Baogui Xin

Copyright (C) 2021 Jing Fan and Jiafu Su. This is an open access article distributed under the Creative Commons Attribution License, which permits unrestricted use, distribution, and reproduction in any medium, provided the original work is properly cited.

\begin{abstract}
Entrepreneurial opportunity recognition is a key focus of entrepreneurship research and has received considerable attention in recent years. Previous research has highlighted that social network strength, need knowledge, and technological knowledge are important factors in entrepreneurial opportunity recognition and that these factors in isolation cannot sufficiently explain how entrepreneurial opportunities are recognized. Nonetheless, little is known about the effect that social network strength may exert on entrepreneurial opportunity recognition through need knowledge and technological knowledge. Building on social network theory, this study develops and examines a chain mediation model that incorporates need knowledge and technological knowledge into the relationship between social network strength and entrepreneurial opportunity recognition. The results of this study demonstrate that the effect of social network strength on entrepreneurial opportunity recognition can be partitioned into the direct and indirect effects. In particular, the effect of social network strength on entrepreneurial opportunity recognition is mediated by need knowledge, not by technological knowledge. Moreover, need knowledge and technological knowledge play a continuous mediating role in the relationship between social network strength and entrepreneurial opportunity recognition. These findings extend the entrepreneurial opportunity recognition literature by casting light on the knowledge conduits linking social network strength to entrepreneurial opportunity recognition.
\end{abstract}

\section{Introduction}

Entrepreneurship is an engine that drives economic growth [1]. Entrepreneurial activity concerns the launching of products or services that differ from existing ones [2]. The launching of products or services begins with entrepreneurial opportunity recognition. Entrepreneurial opportunity recognition refers to the identification of a practicable profit-seeking venture [3]. It is a potential access to competitive advantage [4] and of central importance to entrepreneurial ability [5]. In this regard, entrepreneurial opportunity recognition stands out as the keystone of entrepreneurship.

Although entrepreneurial opportunity recognition is generally viewed as an activity conducted by entrepreneurs; in practice, entrepreneurial opportunities can also be recognized by employees $[6,7]$. Social networks that employees are embedded in vary in terms of attributes, and these differences bring about different potential for the recognition of entrepreneurial opportunities [8]. An important attribute of social network concerns the strength of social network. Social network strength refers to the frequency of interactions and the intensity of trust in relationships $[9,10]$. The notion that social network strength is a key factor in entrepreneurial opportunity recognition has been widely accepted [11]. However, the relationship between social network strength and entrepreneurial opportunity recognition has not been fully explored.

First, research on entrepreneurial opportunity recognition has devoted efforts to inquiring the role of social 
network strength of entrepreneurs, whereas social network strength of employees has received little attention in empirical studies. Extant research has pointed out that social network strength is important for entrepreneurs to recognize entrepreneurial opportunities $[12,13]$. From the perspective of employees, a significant question is whether employees' social network strength affects their recognition of entrepreneurial opportunity. However, previous research is devoid of work that probes into the relationship between social network strength and entrepreneurial opportunity recognition from a perspective of employees.

Second, little is known about the mediating mechanism through which social network strength may exert its effect on entrepreneurial opportunity recognition because previous research has mainly addressed the direct effect of social network strength on entrepreneurial opportunity recognition. Employees with different social network strengths will receive different knowledge through various levels of interactions with other actors $[9,14]$. An employee's prior knowledge constitutes a knowledge conduit that leads to the recognition of entrepreneurial opportunities [15]. This implies that social network strength may affect entrepreneurial opportunity recognition through its effect on prior knowledge. However, there is little explication of the mediating role of prior knowledge in the relationship between social network strength and entrepreneurial opportunity recognition.

To fill in the above-mentioned research gaps, this study develops a chain mediation model that elaborates the mechanism through which social network strength transmits its effect to entrepreneurial opportunity recognition. Specifically, this study examines the mediating roles of two dimensions of prior knowledge in the relationship between social network strength and entrepreneurial opportunity recognition. First, this study focuses on the mediating role of need knowledge. Need knowledge refers to the knowledge about use-related problems and unmet needs stemming from current and future customers [16]. It was selected because it captures market-related knowledge, which is germane to entrepreneurial opportunity recognition. Second, this study incorporates technological knowledge into the mediating mechanism. Technological knowledge can be defined as the amount of technological knowledge in a specific domain [17]. It was chosen because employees rely on their technological knowledge to offer workable solutions to customers' needs. Third, this study examines the chain mediation model at the employee level, exploring the effect of social network strength on entrepreneurial opportunity recognition from a perspective that differs from previous research.

This study seeks to advance the entrepreneurial opportunity recognition literature by demonstrating the knowledge corridors linking social network strength to entrepreneurial opportunity recognition. This is one of a few studies that employ a chain mediation model to grasp more complicated mediating roles of need knowledge and technological knowledge. This study also focuses on employees. Such a focused study is considerably more helpful than previous studies.

This study proceeds as follows. Firstly, a review of the literature is presented, and hypotheses are developed. Following this, the methodological design of this study is described. Then, the results of data analysis and hypothesis test are presented. Finally, a conclusion of this study is offered.

\section{Literature Review and Research Hypotheses}

2.1. Entrepreneurial Opportunity Recognition. Research has primarily investigated entrepreneurial opportunity recognition at the individual level and has stressed the effects of individual-level factors on entrepreneurial opportunity recognition [18]. The individual level comprises the persons who recognize entrepreneurial opportunities. In general, empirical attention has centred on entrepreneurs.

In practice, however, entrepreneurial opportunities can be recognized by employees. This implies that focusing narrowly on entrepreneurs could lead to an incomplete view of entrepreneurial opportunity recognition. To cast new light on entrepreneurial opportunity recognition, this study focuses on employee, specifically on the question whether employees' social network strength affects their recognition of entrepreneurial opportunities through need knowledge and technological knowledge.

\subsection{Social Network Strength and Entrepreneurial Opportunity} Recognition. According to social network theory, relationships could be categorized into either strong ties or weak ties [19]. Long-term and frequent interactions among employees result in strong ties. Employees usually invest time and affection in maintaining strong ties, and they manage to ensure a high level of mutual trust and reciprocity [19]. Conversely, weak ties are easier to maintain as a result of their low maintenance costs.

Social network strength may be positively related to entrepreneurial opportunity recognition for two reasons. First, employees involved in strong ties are willing to put forth effort in the form of transferring knowledge, which eases the transfer of knowledge [10, 20]. As a result, knowledge is transferred in a timely manner, and the accuracy of knowledge is improved in such a manner [21]. Strong ties increase the chances of obtaining fine-grained and complex knowledge [9]. Because its validity is high, finegrained knowledge can be applied to use immediately and helps to seize entrepreneurial opportunities. Second, employees embedded in strong ties have high intrinsic motivation to take part in work-related interactions [22]. Intrinsic motivation of both the recipient and the source is conducive to the development of creative ideas [23]. Thus, strong ties are instrumental in developing creative ideas, which in turn may contribute to the recognition of entrepreneurial opportunities.

The first hypothesis is based on the above arguments:

H1: social network strength has a positive direct effect on entrepreneurial opportunity recognition

2.3. The Mediating Role of Need Knowledge. Need knowledge refers to the extent to which an employee is knowledgeable about use-related problems and unmet needs stemming 
from current and future customers [16]. This knowledge is usually held by customers or users. However, employees can learn customers' needs through interaction with customers or other actors in the market [24]. Social network strength may be positively associated with need knowledge for two reasons. First, strong ties are characterized by two-way interactions between the recipient and the source [25]. Because need knowledge may be sticky [24], the recipient might not fully assimilate the knowledge during the initial interaction with the customers. The two-way interactions offer an iterative process in which there are multiple chances to assimilate the knowledge. Second, strong ties facilitate the communication of noncodified knowledge [26]. Need knowledge may be tacit. Tacitness impedes the transfer of need knowledge because tacit knowledge is difficult to articulate and codify [27]. Employees with strong ties understand each other and establish a heuristic way of communicating noncodified knowledge between them [9].

According to Austrian economics, employees have distinct prior knowledge that enables them to recognize certain entrepreneurial opportunities [15]. This study contends that this view applies to need knowledge. First, increased knowledge about customers' needs allows employees to understand customers' specific needs and gives employees a clear advantage of articulating customers' specific needs. As employees have more need knowledge, they become increasingly efficient at centring attention on customers' specific needs that contribute to the recognition of entrepreneurial opportunities [28]. Second, employees with more need knowledge appear to think in a more empathetic way, which allows employees to empathize with customers [16]. Through empathizing with customers, employees identify customers' expectations with regard to the products or services that satisfy customers' specific needs, leading to the recognition of entrepreneurial opportunities [28, 29].

The above arguments suggest the following hypothesis:

$\mathrm{H} 2$ : need knowledge mediates the relationship between social network strength and entrepreneurial opportunity recognition

2.4. The Mediating Role of Technological Knowledge. Technological knowledge refers to the extent to which an employee has knowledge about technology in a specific domain [17]. Social network strength may be positively related to technological knowledge for two reasons. First, employees with strong ties tend to develop reciprocal arrangements [22]. When employees acquire technological knowledge, there is unplanned need for the access to others to obtain extra help and advice. Because employees who engage in reciprocal arrangements are more likely to assist at a moment's notice, extra help and advice are available in strong ties $[9,30]$. Second, technological knowledge can be complex and fine grained. Strong ties are more helpful in transferring fine grained and complex knowledge than weak ties $[9,31]$.

This study also assumes that technological knowledge contributes to the recognition of entrepreneurial opportunities. First, entrepreneurial opportunity recognition can be viewed as a process of solving problems [32]. Employees with higher levels of technological knowledge are more proficient in solving problem [33]. Technological knowledge enables employees to break a problem into a series of subproblems that are more promising for the elaboration of new ideas [34]. Second, increased technological knowledge leads to a complex knowledge structure, providing employees with richer knowledge linkages [17]. These linkages facilitate the recognition of entrepreneurial opportunities [35].

The above arguments suggest the following hypothesis:

H3: technological knowledge mediates the relationship between social network strength and entrepreneurial opportunity recognition

\subsection{The Continuous Mediating Role of Need Knowledge and} Technological Knowledge. Need knowledge is an antecedent to technological knowledge in the process of entrepreneurial opportunity recognition because an employee adds technological knowledge to facilitate the process of entrepreneurial opportunity recognition, which may begin with need knowledge [15]. First, employees with detailed need knowledge develop a good sense of market trends and further identify technological changes that are in keeping with market trends. Second, a high level of need knowledge provides rich knowledge attributes, increasing the number of possible linkages with technological knowledge [17]. Therefore, this study assumes that need knowledge is positively associated with technological knowledge.

In addition, this study also maintains that social network strength is positively associated with need knowledge and that technological knowledge contributes to entrepreneurial opportunity recognition. Building on the above arguments, this study suggests the following hypothesis:

H4: need knowledge and technological knowledge play a continuous mediating role in the relationship between social network strength and entrepreneurial opportunity recognition

The conceptual model of this study is depicted in Figure 1.

\section{Research Methods}

3.1. Empirical Context and Data Collecting. The empirical context of this study features employees of IT firms in Beijing, China. This context is ideal for examining the proposed hypotheses. First, entrepreneurial opportunity recognition is an issue that should be investigated in a given institutional environment, in view of the broad set of country-level and industry-level factors [36]. Second, previous research on entrepreneurial opportunity recognition has typically focused on entrepreneurs. In contrast, this study focuses on employees because entrepreneurial opportunities may also be recognized by employees. Third, employees of IT firms are characterized by various levels of social network strength, need knowledge, and technological knowledge, showing sufficient variations in these individual-level factors. Overall, this setting provides an ideal context for this study. 


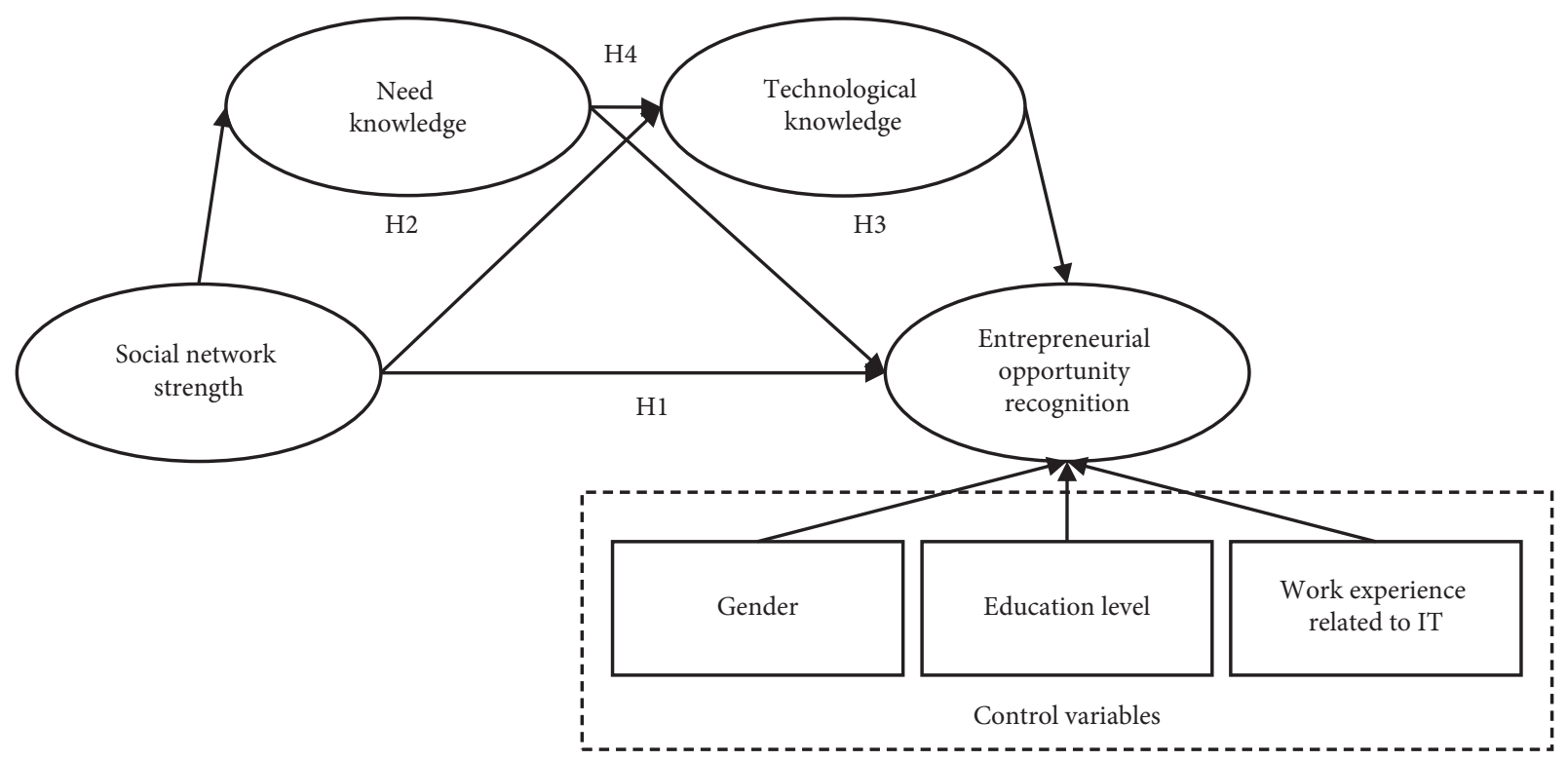

FIgure 1: Conceptual model.

This study collected the data online with the aid of a research firm whose clients are widely distributed throughout different industries and regions in China. The online questionnaire was placed on the website of the research firm. The inclusion criteria for the sample were as follows: (1) employees of IT firms located in Beijing and (2) agreed to participate in the survey. Two parts composed the questionnaire. The first part consisted of screening questions. Respondents' answers to the screening questions must be consistent with the inclusion criteria. If not, the respondents will not be requested to proceed with the survey. The second part consisted of questions about demographic data and measures employed by this study; 369 questionnaires were collected, and 348 usable questionnaires were retained, indicating a $94.31 \%$ valid response rate. Nonresponse bias was examined by carrying out chi-square test on key demographic characteristics (gender and educational level) between the early 25 percent and the last 25 percent of the respondents [37]. These two groups do not differ in key demographic characteristics, indicating that nonresponse bias is not a major concern here. Table 1 details the demographics of respondents.

3.2. Measures. Previously established scales were adapted to measure the constructs. Because the initial measures were prepared in English, the translation/back-translation method was adopted to enhance the validity of the Chineseversion measures. The Chinese-version measures were refined to ensure their fitness for the economic reality of China. Except for the items of social network strength, this study used seven-point Likert scales ( 1 = "strongly disagree," 7 = "strongly agree") to measure responses to each item of constructs.

This study operationalized social network strength as an indicator measuring interaction frequency and trust intensity in the relationships that an employee possesses
$[9,10,38]$. The measure of social network strength was derived from Fernández-Pérez et al. [38]. Respondents were requested to assess their relationships with staff at other firms, government officials, and staff of finance/trade organizations. First, respondents were requested to assess the frequency of interactions with these actors. For this case, a seven-point Likert scale varying between $1=$ "less than once every two months" and $7=$ "daily" was provided. Second, respondents were requested to assess the intensity of trust in relationships with these actors. For this case, a seven-point Likert scale varying between $1=$ "distant" and 7 = "trustworthy" was provided. A respondent's assessments of these two aspects were averaged to form a composite measure of the strength of relationships with the actors in each category. Considering that trust intensity and interaction frequency are two important aspects of social network strength, an approach that takes into account both aspects seems appropriate if social network strength's effect on entrepreneurial opportunity recognition is examined.

The four-item scale of need knowledge was based on the work of Marvel and Lumpkin [32], reflecting the degree to which respondents are knowledgeable about customers' needs. Two examples of the items are "My knowledge of different customers' needs is rich" and "I have a lot of knowledge of ways customers use our products or services."

As most of the established scales of technological knowledge are organizational level, this study draws on previous research with a similar focus. Based on the work of Yang et al. [39] and of Flynn and Goldsmith [40], this study used four items to measure the degree to which respondents are knowledgeable about technological knowledge in a specific domain. Two examples of the items are "I am highly familiar with technological knowledge in my domain" and "I have acquired a great deal of experience in my domain."

On the basis of the work by Shane et al. [41], entrepreneurial opportunity recognition was measured with four items that reflect the degree to which an employee is able to recognize 
TABLE 1: Demographics of respondents.

\begin{tabular}{|c|c|c|c|}
\hline Measure & Category & Frequency & Percentage (\%) \\
\hline \multirow{2}{*}{ Gender } & Male & 173 & 49.71 \\
\hline & Female & 175 & 50.29 \\
\hline \multirow{5}{*}{ Age } & Less than 31 & 210 & 60.34 \\
\hline & 31 to 40 & 127 & 36.49 \\
\hline & 41 to 50 & 9 & 2.59 \\
\hline & 51 to 60 & 1 & 0.29 \\
\hline & More than 60 & 1 & 0.29 \\
\hline \multirow{4}{*}{ Education level } & High school degree & 10 & 2.87 \\
\hline & Bachelor degree & 267 & 76.73 \\
\hline & Master degree & 67 & 19.25 \\
\hline & Ph.D. degree & 4 & 1.15 \\
\hline \multirow{6}{*}{ Work experience related to IT } & 3 or less than 3 & 116 & 33.33 \\
\hline & 4 to 6 & 116 & 33.33 \\
\hline & 7 to 9 & 68 & 19.54 \\
\hline & 10 to 12 & 31 & 8.92 \\
\hline & 13 to 15 & 10 & 2.87 \\
\hline & 16 or more than 16 & 7 & 2.01 \\
\hline
\end{tabular}

entrepreneurial opportunities. Two examples of the items are "I thought of several ideas for new businesses in the last month" and "I often identify ideas that can materialize into new products or services (even though I may not pursue them)."

This study controlled gender, education level, and working experience related to IT because these individual differences may potentially influence the recognition of entrepreneurial opportunities [42]. Gender was coded: $0=$ female, $1=$ male. Education level was coded: $1=$ high school degree, 2 =bachelor degree, $3=$ master degree, and $4=$ Ph.D. degree. Six codes ranging from 1 to 6 were created to control for work experience related to IT: 3 years or less, between 4 and 6 years, between 7 and 9 years, between 10 and 12 years, between 13 and 15 years, and 16 years or above.

\section{Data Analysis and Hypothesis Test}

With the aid of software SPSS 24.0 and AMOS 24.0, preliminary analysis and hypothesis test were conducted. Even though the three-step method recommended by Baron and Kenny [43] is the most widely used approach to testing mediation, this method is low in power compared with the bootstrap procedure $[44,45]$. The use of the bootstrap procedure can also address the presence of nonnormal data when mediation is assessed [46]. Thus, this study examined the proposed hypotheses by performing the bootstrap procedure with structural equation modeling (SEM).

4.1. Common Method Bias. Survey-based research is likely to be influenced by common method bias. To minimize the potential of common method bias, this study took some procedural prevention and conducted statistical tests as suggested by Podsakoff et al. [47]. First, respondents provided their responses in an anonymous manner, and they were told that there were no right or wrong responses. Second, Harman's single factor analysis was carried out. Four factors with eigenvalues above 1 were extracted, accounting for $63.136 \%$ of the total variance. The first unrotated factor explained
$35.797 \%$ of the total variance. No single factor that individually explained most of the total variance emerged, suggesting that common method bias does not severely impact the results of this study. Third, a more advanced Harman's single factor analysis, loading all items on a single factor in a confirmatory factor analysis (CFA), was conducted. This model shows a poor fit $(\mathrm{CFI}=0.655$, RMSEA $=0.145)$, providing further support for the argument that this study is not severely impacted by common method bias.

4.2. Factor Analysis. A CFA of the proposed measurement model was performed. The fit indices of this model are $X^{2} /$ $\mathrm{df}=1.916$, GFI $=0.935, \mathrm{CFI}=0.945$, and $\mathrm{RMSEA}=0.051$, suggesting a satisfactory fit between the proposed measurement model and the data. The factor loadings for all items are statistically significant in the predictive direction by the critical ratio test $(p<0.001)$. All of the standardized factor loadings range between 0.552 and 0.920 , meeting the acceptable value of 0.50 suggested by Hair et al. [48].

4.3. Reliability and Validity Test. The descriptive statistics, correlation matrix, and the results of reliability and validity test for all variables are reported in Table 2. To assess the reliability of a latent construct, the coefficient of Cronbach's alpha was calculated. As Table 2 shows, the coefficient of Cronbach's alpha for each latent construct is above 0.70, indicating that each construct is reliable.

This study used both composite reliability (CR) and average variance extracted (AVE) to measure convergent validity of a construct. As shown in Table 2 , all the values of $\mathrm{CR}$ are acceptable according to the 0.70 guideline proposed by Fornell and Larcker [49]. Although the value of AVE for social network strength exceeds the 0.50 criterion suggested by Fornell and Larcker [49], the values of AVE for the other constructs are below the 0.50 criterion, ranging from 0.414 to 0.468. AVE is more conservative than CR. Convergent validity of a construct may be adequate, even though the 
TABLE 2: Descriptive statistics, correlation matrix, reliability, and validity test.

\begin{tabular}{|c|c|c|c|c|c|c|c|c|c|c|c|c|}
\hline Variable & Alpha & CR & AVE & Mean & SD & GEN & EDU & EXP & SNS & NK & TK & EOR \\
\hline GEN & & & & 0.497 & 0.501 & & & & & & & \\
\hline EDU & & & & 2.187 & 0.483 & -0.004 & & & & & & \\
\hline EXP & & & & 2.210 & 1.194 & 0.020 & -0.022 & & & & & \\
\hline SNS & 0.864 & 0.875 & 0.703 & 3.666 & 1.211 & 0.103 & 0.175 & 0.000 & 0.838 & & & \\
\hline NK & 0.723 & 0.736 & 0.414 & 5.435 & 0.903 & 0.111 & -0.038 & 0.093 & 0.361 & 0.643 & & \\
\hline TK & 0.747 & 0.747 & 0.428 & 5.498 & 0.908 & 0.180 & 0.016 & 0.283 & 0.292 & 0.678 & 0.654 & \\
\hline EOR & 0.774 & 0.775 & 0.463 & 5.037 & 1.089 & 0.140 & 0.126 & 0.058 & 0.451 & 0.725 & 0.664 & 0.680 \\
\hline
\end{tabular}

Note. $\mathrm{SD}=$ standard deviation, Alpha $=$ Cronbach's alpha, AVE $=$ average variance extracted, $\mathrm{CR}=$ composite reliability, $\mathrm{GEN}=$ gender, $\mathrm{EDU}=\mathrm{education}$ level, EXP = work experience related to IT, SNS = social network strength, NK = need knowledge, TK = technological knowledge, and EOR = entrepreneurial opportunity recognition. The square root of AVE is in bold and reported along the leading diagonal of the correlation matrix of constructs.

TABLE 3: Discriminant validity: comparing measurement models.

\begin{tabular}{|c|c|c|c|c|c|c|c|}
\hline Model & $\begin{array}{c}\text { Description } \\
\end{array}$ & $X^{2}$ & df & $\Delta X^{2}$ & CFI & IFI & RMSEA \\
\hline Model 1 & $\begin{array}{l}\text { Four factors and three control variables: SNS, NK, TK, EOR, GEN, EDU, and } \\
\qquad \text { EXP }\end{array}$ & 224.152 & 117 & & 0.945 & 0.946 & 0.051 \\
\hline Model 2 & $\begin{array}{c}\text { Three factors and three control variables: NK and TK were combined into } \\
\text { one factor }\end{array}$ & 314.509 & 123 & $90.357^{* * *}$ & 0.902 & 0.903 & 0.067 \\
\hline Model 3 & $\begin{array}{c}\text { Three factors and three control variables: NK and EOR were combined into } \\
\text { one factor }\end{array}$ & 298.855 & 123 & $74.703^{* * *}$ & 0.910 & 0.911 & 0.064 \\
\hline Model 4 & $\begin{array}{c}\text { Three factors and three control variables: TK and EOR were combined into } \\
\text { one factor }\end{array}$ & 338.086 & 123 & $113.934^{* * *}$ & 0.890 & 0.891 & 0.071 \\
\hline
\end{tabular}

Note. $\mathrm{GEN}=$ gender, $\mathrm{EDU}=$ education level, $\mathrm{EXP}=$ work experience related to IT, $\mathrm{SNS}=$ social network strength, $\mathrm{NK}=$ need knowledge, $\mathrm{TK}=$ technological knowledge, and $\mathrm{EOR}=$ entrepreneurial opportunity recognition. ${ }^{* * *} p<0.001$ (two-tailed).

value of AVE for this construct does not meet the 0.50 criterion $[49,50]$. Considering the value of CR for each construct is well above 0.70 , convergent validity of each construct is adequate.

A rigorous test of discriminant validity is to establish that the square root of AVE for each latent construct exceeds the interconstruct correlations [49]. The square roots of AVEs for need knowledge, technological knowledge, and entrepreneurial opportunity recognition are slightly below the highest correlations with other constructs (i.e., 0.678, 0.725, and 0.664 , see Table 2). For these constructs, an additional test suggested by De Luca and Atuahene-Gima [27] was conducted. The proposed measurement model (i.e., model 1) was examined against three alternative measurement models (i.e., model 2, model 3, and model 4). As Table 3 reports, there are significant differences between the proposed measurement model and alternative measurement models, indicating that the pattern of factor loadings differs significantly across the models. Model 1 fits the data best among all models. Taken together, the results provide support for acceptable levels of discriminant validity of the latent constructs.

4.4. Hypothesis Test. The bootstrap procedure was conducted. The resampling process was repeated for 5000 times, which was recommended by Hayes [45]. Both percentile confidence interval and bias-corrected confidence interval are $95 \%$. The fit indices demonstrate that the structural equation model provides a reasonable fit to the data $\left(X^{2}\right.$ $(123)=256.801, \quad$ GFI $=0.926, \quad \mathrm{IFI}=0.932, \quad \mathrm{TLI}=0.915$, $\mathrm{CFI}=0.931, \mathrm{SRMR}=0.066, \mathrm{RMSEA}=0.056$ ).
As Table 4 shows, although social network strength is positively related to need knowledge $(b=0.158, p<0.001)$ and entrepreneurial opportunity recognition $(b=0.132, p<0.01)$, it is not positively related to technological knowledge $(b=0.040$, $p>0.05)$. Need knowledge positively affects technological knowledge $(b=1.024, p<0.001)$ and entrepreneurial opportunity recognition $(b=0.775, \quad p<0.001)$. Technological knowledge has a positive and significant effect on entrepreneurial opportunity recognition $(b=0.353, p<0.001)$. Among the control variables, only educational level could help in recognizing entrepreneurial opportunities $(b=0.198, p<0.05)$. The influences of gender $(b=0.057, p>0.05)$ and work experience $(b=-0.046, p>0.05)$ on entrepreneurial opportunity recognition are not significant. The variance explained is 13.0 percent for need knowledge, 46.4 percent for technological knowledge, and 63.9 percent for entrepreneurial opportunity recognition. The path coefficients of structural equation model are presented in Figure 2.

Table 5 reports the results of hypotheses testing. The direct effect of social network strength on entrepreneurial opportunity recognition is 0.132 , with $95 \%$ bias-corrected confidence interval [0.051-0.217] and 95\% percentile confidence interval [0.047-0.212], excluding zero. So H1 is supported. The indirect effect of social network strength on entrepreneurial opportunity recognition via need knowledge is 0.122 , with $95 \%$ bias-corrected confidence interval [0.055$0.219]$ and $95 \%$ percentile confidence interval [0.052-0.214] excluding zero. Thus, $\mathrm{H} 2$ is thus supported. The indirect effect of social network strength on entrepreneurial opportunity recognition via technological knowledge is 0.014 , with $95 \%$ bias-corrected confidence interval $[-0.010$ to $0.067]$ and $95 \%$ percentile confidence interval $[-0.013$ to 
TABLE 4: Coefficient estimates for the structural equation model.

\begin{tabular}{lcr}
\hline Path & Coefficient & SE \\
\hline SNS $\longrightarrow$ NK & $0.158^{* * *}$ & 0.031 \\
SNS $\longrightarrow$ TK & 0.040 & 0.043 \\
$\mathrm{NK} \longrightarrow$ TK & $1.024^{* * *}$ & 0.144 \\
SNS $\longrightarrow$ EOR & $0.132^{* *}$ & 0.042 \\
$\mathrm{NK} \longrightarrow$ EOR & $0.775^{* * *}$ & 0.178 \\
$\mathrm{TK} \longrightarrow$ EOR & $0.353^{* * *}$ & 0.105 \\
$\mathrm{GEN} \longrightarrow$ EOR & 0.057 & 0.095 \\
$\mathrm{EDU} \longrightarrow$ EOR & $0.198^{*}$ & 0.100 \\
$\mathrm{EXP} \longrightarrow$ EOR & -0.046 & 0.040 \\
$R^{2}$ & \multicolumn{1}{c}{$\mathrm{NK}\left(R^{2}=0.130\right) ; \mathrm{TK}\left(R^{2}=0.464\right) ; \mathrm{EOR}\left(R^{2}=0.639\right)$} \\
\hline
\end{tabular}

Note. Coefficients are unstandardized coefficients. $\mathrm{SE}=$ standard error, $\mathrm{SNS}=$ social network strength, $\mathrm{EOR}=$ entrepreneurial opportunity recognition, $\mathrm{NK}=$ need knowledge, TK $=$ technological knowledge, GEN $=$ gender, EDU $=$ education level, and EXP $=$ work experience related to IT. ${ }^{* * *} p<0.001,{ }^{* *} p<0.01$, and ${ }^{*} p<0.05$ (two-tailed).

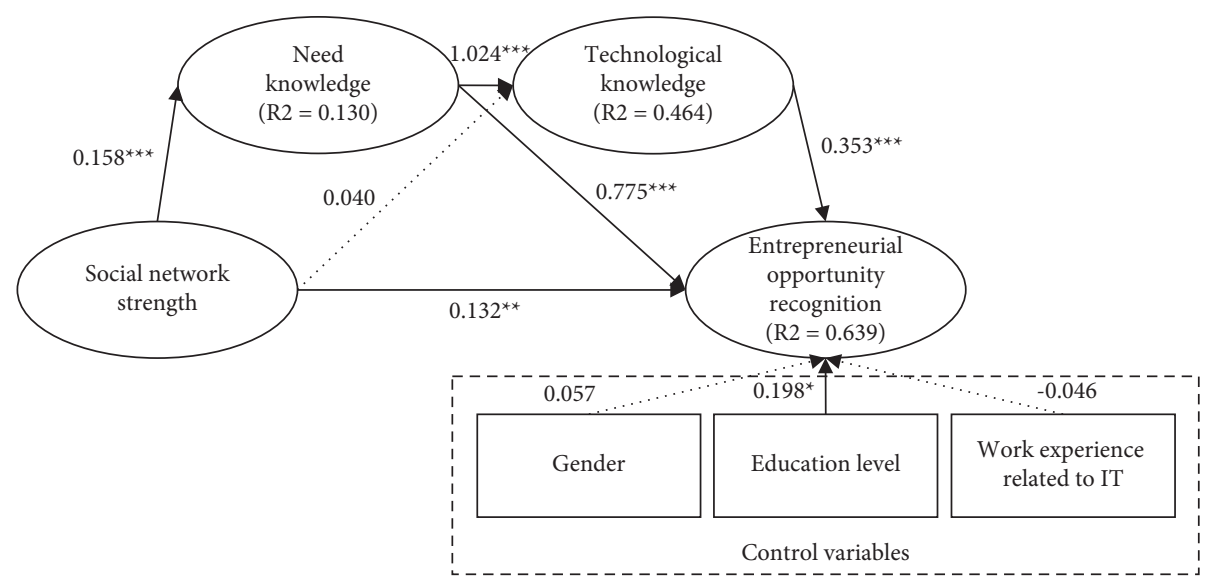

Figure 2: Structural equation model with results. Note. Coefficients are unstandardized coefficients. Nonsignificant paths are represented by dotted lines. ${ }^{* * *} p<0.001,{ }^{* *} p<0.01$, and ${ }^{*} p<0.05$ (two-tailed).

TABLE 5: Results of hypothesis test.

\begin{tabular}{lccccccc}
\hline \multirow{2}{*}{ Path } & \multirow{2}{*}{ Effect } & \multirow{2}{*}{ Bootstrap SE } & \multicolumn{2}{c}{$95 \%$ bias-corrected CI } & \multicolumn{3}{c}{$95 \%$ percentile CI } \\
& & & Lower bound & Upper bound & Lower bound & Upper bound & Conclusion \\
\hline $\mathrm{H} 1: \mathrm{SNS} \longrightarrow \mathrm{EOR}$ & 0.132 & 0.042 & 0.051 & 0.217 & 0.047 & 0.212 & Supported \\
$\mathrm{H} 2: \mathrm{SNS} \longrightarrow \mathrm{NK} \longrightarrow$ EOR & 0.122 & 0.041 & 0.055 & 0.219 & 0.052 & 0.214 & Supported \\
$\mathrm{H} 3: \mathrm{SNS} \longrightarrow \mathrm{TK} \longrightarrow \mathrm{EOR}$ & 0.014 & 0.018 & -0.010 & 0.067 & -0.013 & 0.059 & Not supported \\
$\mathrm{H} 4: \mathrm{SNS} \longrightarrow \mathrm{NK} \longrightarrow \mathrm{TK} \longrightarrow$ EOR & 0.057 & 0.026 & 0.019 & 0.125 & 0.013 & 0.114 & Supported \\
\hline
\end{tabular}

Note. Effects are unstandardized effects. $\mathrm{SE}=$ standard error, $\mathrm{CI}=$ confidence interval, $\mathrm{SNS}=$ social network strength, EOR = entrepreneurial opportunity recognition, $\mathrm{NK}=$ need knowledge, and $\mathrm{TK}=$ technological knowledge.

0.059], including zero. So H3 is not supported. The indirect effect of social network strength on entrepreneurial opportunity recognition via need knowledge and technological knowledge is 0.057 , with $95 \%$ bias-corrected confidence interval [0.019-0.125] and 95\% percentile confidence interval [0.013-0.114], excluding zero. Thus, H4 is supported. Because the direct effect (i.e., H1) and the indirect effects (i.e., $\mathrm{H} 2$ and H4) are significant at the same direction, the mediation established in this study is complementary [44].

\section{Conclusions}

The chain mediation model proposed by this study attempts to describe the knowledge corridors through which social network strength transmits its effect to entrepreneurial opportunity recognition. The total effect of social network strength was not examined in this study because a significant total effect is not a precondition for establishing mediation $[44,45]$. The results of this study suggest three conclusions. First, social network strength facilitates entrepreneurial opportunity recognition, in part due to mediating mechanisms. Second, need knowledge mediates the relationship between social network strength and entrepreneurial opportunity recognition, whereas technological knowledge does not. Third, need knowledge and technological knowledge play a continuous mediating role in the relationship between social network strength and entrepreneurial opportunity recognition. 
This study provides no evidence that technological knowledge mediates the relationship between social network strength and entrepreneurial opportunity recognition. The mediating role of technological knowledge is not significant due to the lack of a relationship between social network strength and technological knowledge. A possible explanation is that social network strength is only one of the possible sources of technological knowledge relevant for entrepreneurial opportunity recognition. Employees of IT firms rely on education and training to acquire technological knowledge because education and training are important investments in human capital [51]. Therefore, social network strength is less likely to be related to technological knowledge.

5.1. Theoretical Contributions. Although set in the context of China's IT industry, this study is founded on a theoretical interest in revealing the effects of individual-level factors on entrepreneurial opportunity recognition. This study contributes to entrepreneurial opportunity recognition research by building and examining a chain mediation model of how need knowledge and technological knowledge mediate the relationship between social network strength and entrepreneurial opportunity recognition.

First, this model sheds new light on the importance of strong ties in entrepreneurial opportunity recognition. Typically, previous studies that have empirically examined the effect of social network strength on entrepreneurial opportunity recognition from a perspective of entrepreneurs have suggested that weak ties matter, such as the work of Arenius and Clercq [8]. In contrast, this model focuses on social network strength from the perspective of employees. Specifically, the findings of this model provide evidence suggesting that strong ties with three types of actors lead to positive gains in entrepreneurial opportunity recognition. This finding is contrary to the results of previous studies, whereas it is significant. The findings of this model underscore the need for entrepreneurial opportunity recognition research to place more importance on strong ties.

Second, this model provides a more nuanced notion of the mediating mechanisms through which the positive effect of social network strength on entrepreneurial opportunity recognition develops. The direct effect of social network strength has been previously validated in different contexts. In contrast, the findings of this model clarify why social network strength matters in entrepreneurial opportunity recognition by showing simultaneously its direct and indirect effects. Specifically, the findings of this model highlight that the indirect effect of social network strength can be partitioned into the indirect effect through need knowledge and the indirect effect through need knowledge and technological knowledge. This implies that examining only the direct effect of social network strength leads to an erroneous notion of its effect.

Third, this model unearths additional insights into the mediating roles of need knowledge and technological knowledge in entrepreneurial opportunity recognition. Prior knowledge has been previously viewed as a moderator in entrepreneurial opportunity recognition [52]. In contrast, the findings of this model suggest that need knowledge converts some social network strength into not only entrepreneurial opportunity recognition but also technological knowledge, which in turn contributes to entrepreneurial opportunity recognition. Moreover, the findings of this model indicate that need knowledge and technological knowledge play different roles in entrepreneurial opportunity recognition by partially mediating the effect of social network strength, providing a more fine-grained view of the role of prior knowledge in entrepreneurial opportunity recognition.

5.2. Managerial Implications. This study has several recommendations for employees in China. First, this study calls on employees to attach importance to strong ties. The positive effect of social network strength on entrepreneurial opportunity recognition established by this study suggests that strong ties are instrumental in entrepreneurial opportunity recognition. An employee is best served by cultivating strong ties with staff at other firms, government officials, and staff of finance/trade organizations to recognize entrepreneurial opportunities. Second, the results suggest that it is the mediating mechanisms that complete the translation of social network strength into positive gains in entrepreneurial opportunity recognition. This means that employees who neglect the mediating mechanisms cannot achieve the desired effect. Third, employees should place more weight on need knowledge and technological knowledge in the process of entrepreneurial opportunity recognition. They should strive to acquire more need knowledge through frequent interactions with others and dig deeper into technological knowledge so as to recognize entrepreneurial opportunities. Fourth, employees should rely on strong ties to acquire need knowledge. Nonetheless, social network strength does not provide employees access to technological knowledge.

5.3. Limitations and Future Research. There are several limitations that may offer directions for further research in this study. First, this is a cross-sectional analysis, which has its limitation. This study can only examine relationships, not causal relationships. Further research might benefit from longitudinal analysis.

Second, another limitation may arise from the employment of self-report data. Social desirability problem is a potential problem in self-report data [53]. Thus, employing some more sophisticated quantitative approaches may merit further research.

Third, the choice of a particular industry in a given country may give rise to the issue of generalizability. Further research should assess the generalizability of the results of this study in other contexts.

\section{Data Availability}

The data used to support the findings of this study are included within the article. 


\section{Conflicts of Interest}

The authors declare that they have no conflicts of interest regarding the publication of this study.

\section{Acknowledgments}

This work was supported by the National Natural Science Fund of China (Grant no. 72062001) and the Youth Foundation of Ministry of Education of China (19YJC630141).

\section{References}

[1] Z. J. Acs, "Small business economics: a global perspective," Challenge, vol. 35, no. 6, pp. 38-44, 1992.

[2] D. A. Grégoire and D. A. Shepherd, "Technology-market combinations and the identification of entrepreneurial opportunities: an investigation of the opportunity-individual nexus," Academy of Management Journal, vol. 55, no. 4, pp. 753-785, 2012.

[3] R. P. Singh, "A comment on developing the field of entrepreneurship through the study of opportunity recognition and exploitation," Academy of Management Review, vol. 26, no. 1, pp. 10-12, 2001.

[4] S. A. Alvarez and L. W. Busenitz, "The entrepreneurship of resource-based theory," Journal of Management, vol. 27, no. 6, pp. 755-775, 2001.

[5] A. Ardichvili, R. Cardozo, and S. Ray, "A theory of entrepreneurial opportunity identification and development," Journal of Business Venturing, vol. 18, no. 1, pp. 105-123, 2003.

[6] B. Antoncic and R. D. Hisrich, "Clarifying the intrapreneurship concept," Journal of Small Business and Enterprise Development, vol. 10, no. 1, pp. 7-24, 2003.

[7] A. Feldmann and F. Teuteberg, "Intrapreneurship: outside the project box and into the unknown," Journal of Business Strategy, vol. 41, no. 3, pp. 45-55, 2020.

[8] P. Arenius and D. D. Clercq, "A network-based approach on opportunity recognition," Small Business Economics, vol. 24, no. 3, pp. 249-265, 2005.

[9] M. T. Hansen, "The search-transfer problem: the role of weak ties in sharing knowledge across organization subunits," Administrative Science Quarterly, vol. 44, no. 1, pp. 82-111, 1999.

[10] R. Reagans and B. McEvily, "Network structure and knowledge transfer: the effects of cohesion and range," Administrative Science Quarterly, vol. 48, no. 2, pp. 240-267, 2003.

[11] E. Ozgen and R. A. Baron, "Social sources of information in opportunity recognition: effects of mentors, industry networks, and professional forums," Journal of Business Venturing, vol. 22, no. 2, pp. 174-192, 2007.

[12] S. Bhagavatula, T. Elfring, A. van Tilburg, and G. G. van de Bunt, "How social and human capital influence opportunity recognition and resource mobilization in India's handloom industry," Journal of Business Venturing, vol. 25, no. 3, pp. 245-260, 2010.

[13] S. Ren, R. Shu, Y. Bao, and X. Chen, "Linking network ties to entrepreneurial opportunity discovery and exploitation: the role of affective and cognitive trust," The International Entrepreneurship and Management Journal, vol. 12, no. 2, pp. 465-485, 2016.

[14] J. Su, Q. Bai, S. Sindakis, X. Zhang, and T. Yang, "Vulnerability of multinational corporation knowledge network facing resource loss: a super-network perspective," Management Decision, vol. 59, no. 1, pp. 84-103, 2021.

[15] S. Shane, "Prior knowledge and the discovery of entrepreneurial opportunities," Organization Science, vol. 11, no. 4, pp. $448-469,2000$.

[16] T. G. Schweisfurth and C. Raasch, "Absorptive capacity for need knowledge: antecedents and effects for employee innovativeness," Research Policy, vol. 47, no. 4, pp. 687-699, 2018.

[17] P. V. Mannucci and K. Yong, "The differential impact of knowledge depth and knowledge breadth on creativity over individual careers," Academy of Management Journal, vol. 61, no. 5, pp. 1741-1763, 2018.

[18] J. C. Short, D. J. Ketchen, C. L. Shook, and R. D. Ireland, "The concept of "opportunity" in entrepreneurship research: past accomplishments and future challenges," Journal of Management, vol. 36 , no. 1, pp. 40-65, 2010.

[19] M. S. Granovetter, "The strength of weak ties," American Journal of Sociology, vol. 78, no. 6, pp. 1360-1380, 1973.

[20] J. Su, Y. Yang, and X. Zhang, "Knowledge transfer efficiency measurement with application for open innovation networks," International Journal of Technology Management, vol. 81, no. 1-2, pp. 118-142, 2019.

[21] J. S. Coleman, "Social capital in the creation of human capital," American Journal of Sociology, vol. 94, pp. S95-S120, 1988.

[22] P. V. Marsden and K. E. Campbell, "Measuring tie strength," Social Forces, vol. 63, no. 2, pp. 482-501, 1984.

[23] M. E. Sosa, "Where do creative interactions come from? The role of tie content and social networks," Organization Science, vol. 22, no. 1, pp. 1-21, 2011.

[24] E. von Hippel, "“Sticky information” and the locus of problem solving: implications for innovation," Management Science, vol. 40, no. 4, pp. 429-439, 1994.

[25] D. Leonard-Barton and D. K. Sinha, "Developer-user interaction and user satisfaction in internal technology transfer," Academy of Management Journal, vol. 36, no. 5, pp. 11251139, 1993.

[26] B. Uzzi, "Social structure and competition in interfirm networks: the paradox of embeddedness," Administrative Science Quarterly, vol. 42, no. 1, pp. 35-67, 1997.

[27] L. M. D. Luca and K. Atuahene-Gima, "Market knowledge dimensions and cross-functional collaboration: examining the different routes to product innovation performance," Journal of Marketing, vol. 71, no. 1, pp. 95-112, 2007.

[28] J. W. Webb, R. D. Ireland, M. A. Hitt, G. M. Kistruck, and L. Tihanyi, "Where is the opportunity without the customer? An integration of marketing activities, the entrepreneurship process, and institutional theory," Journal of the Academy of Marketing Science, vol. 39, no. 4, pp. 537-554, 2011.

[29] C. Homburg, J. Wieseke, and T. Bornemann, "Implementing the marketing concept at the employee-customer interface: the role of customer need knowledge," Journal of Marketing, vol. 73, no. 4, pp. 64-81, 2009.

[30] X. Zhang and J. Su, "A combined fuzzy DEMATEL and TOPSIS approach for estimating participants in knowledgeintensive crowdsourcing," Computers \& Industrial Engineering, vol. 137, p. 106085, 2019.

[31] J. Su, Y. Yang, and T. Yang, "Measuring knowledge diffusion efficiency in R\&D networks," Knowledge Management Research and Practice, vol. 16, no. 2, pp. 208-219, 2018.

[32] M. R. Marvel and G. T. Lumpkin, "Technology entrepreneurs' human capital and its effects on innovation radicalness," 
Entrepreneurship: Theory and Practice, vol. 31, no. 6, pp. 807-828, 2007.

[33] L. Wang, J. Lin, J. Yan, and W. Cui, "Where do high-impact ideas come from? The interplay between the cumulative knowledge structures and search strategies of researchers," Management Decision, vol. 55, no. 5, pp. 808-825, 2017.

[34] W. F. Boh, R. Evaristo, and A. Ouderkirk, "Balancing breadth and depth of expertise for innovation: a 3M story," Research Policy, vol. 43, no. 2, pp. 349-366, 2014.

[35] D. A. Shepherd and D. R. DeTienne, "Prior knowledge, potential financial reward, and opportunity identification," Entrepreneurship: Theory and Practice, vol. 29, no. 1, pp. 91112, 2005.

[36] D. R. Gnyawali and D. S. Fogel, "Environments for entrepreneurship development: key dimensions and research implications," Entrepreneurship: Theory and Practice, vol. 18, no. 4, pp. 43-62, 1994.

[37] W. Ke, C.-H. Tan, C.-L. Sia, and K.-K. Wei, "Inducing intrinsic motivation to explore the enterprise system: the supremacy of organizational levers," Journal of Management Information Systems, vol. 29, no. 3, pp. 257-290, 2012.

[38] V. Fernández-Pérez, V. J. García-Morales, and Ó. F. BustinzaSánchez, “The effects of CEOs' social networks on organizational performance through knowledge and strategic flexibility," Personnel Review, vol. 41, no. 6, pp. 777-812, 2012.

[39] D. Yang, L. Jin, and S. Sheng, "The effect of knowledge breadth and depth on new product performance," International Journal of Market Research, vol. 59, no. 4, pp. 517-536, 2017.

[40] L. R. Flynn and R. E. Goldsmith, "A short, reliable measure of subjective knowledge," Journal of Business Research, vol. 46, no. 1, pp. 57-66, 1999.

[41] S. Shane, N. Nicolaou, L. Cherkas, and T. D. Spector, "Do openness to experience and recognizing opportunities have the same genetic source?" Human Resource Management, vol. 49, no. 2, pp. 291-303, 2010.

[42] J. Tang, K. M. Kacmar, and L. Busenitz, "Entrepreneurial alertness in the pursuit of new opportunities," Journal of Business Venturing, vol. 27, no. 1, pp. 77-94, 2012.

[43] R. M. Baron and D. A. Kenny, "The moderator-mediator variable distinction in social psychological research: conceptual, strategic, and statistical considerations," Journal of Personality and Social Psychology, vol. 51, no. 6, pp. 11731182, 1986.

[44] X. Zhao, J. G. Lynch Jr, and Q. Chen, "Reconsidering Baron and Kenny: myths and truths about mediation analysis," Journal of Consumer Research, vol. 37, no. 2, pp. 197-206, 2010.

[45] A. F. Hayes, "Beyond Baron and Kenny: statistical mediation analysis in the new millennium," Communication Monographs, vol. 76, no. 4, pp. 408-420, 2009.

[46] P. E. Shrout and N. Bolger, "Mediation in experimental and nonexperimental studies: new procedures and recommendations," Psychological Methods, vol. 7, no. 4, pp. 422-445, 2002.

[47] P. M. Podsakoff, S. B. MacKenzie, J.-Y. Lee, and N. P. Podsakoff, "Common method biases in behavioral research: a critical review of the literature and recommended remedies," Journal of Applied Psychology, vol. 88, no. 5, pp. 879-903, 2003.

[48] J. F. Hair, W. C. Black, B. J. Babin, and R. E. Anderson, Multivariate Data Analysis, Prentice Hall, Upper Saddle River, NJ, USA, 7th ed. edition, 2010.
[49] C. Fornell and D. F. Larcker, "Evaluating structural equation models with unobservable variables and measurement error," Journal of Marketing Research, vol. 18, no. 1, pp. 39-50, 1981.

[50] L. W. Lam, "Impact of competitiveness on salespeople's commitment and performance," Journal of Business Research, vol. 65, no. 9, pp. 1328-1334, 2012.

[51] G. S. Becker, "Investment in human capital: a theoretical analysis," Journal of Political Economy, vol. 70, no. 5, pp. 9-49, 1962.

[52] I. P. Vaghely and P.-A. Julien, "Are opportunities recognized or constructed?” Journal of Business Venturing, vol. 25, no. 1, pp. 73-86, 2010.

[53] P. M. Podsakoff and D. W. Organ, "Self-reports in organizational research: problems and prospects," Journal of Management, vol. 12, no. 4, pp. 531-544, 1986. 